\title{
Avaliações ultrassonográfica e radiográfica dos efeitos da suplementação com dois tipos de probióticos sobre o intestino de cães filhotes
}

[Ultrasonographic and radiographic evaluations of the effects of supplementation with two types of probiotics on the gut of puppies]

\author{
M.A.R. Feliciano ${ }^{1}$, F.M.O.B. Saad ${ }^{2}$, C.A.L. Leite ${ }^{3}$, W.R.R. Vicente ${ }^{4}$, A.C. Nepomuceno ${ }^{1}$, T. Silveira ${ }^{5}$ \\ ${ }^{1}$ Aluno de pós-graduação - FCAV-UNESP - Jaboticabal, SP \\ ${ }^{2}$ Departamento de Zootecnia - UFLA - Lavras, MG \\ ${ }^{3}$ Departamento de Medicina Veterinária - UFLA - Lavras, MG \\ ${ }^{4}$ Faculdade de Ciencias Agrárias e Veterinárias - UNESP - Jaboticabal, SP \\ ${ }^{5}$ Médica veterinária autônoma - Lavras, MG
}

\begin{abstract}
RESUMO
Avaliaram-se os efeitos da suplementação de dois tipos de probióticos para cães filhotes da raça Beagle, que receberam dois tipos de dieta de alta e baixa qualidade, sobre os achados em exames de diagnóstico por imagem. Foram utilizados 18 cães filhotes da raça Beagle, distribuídos em três tratamentos inteiramente ao acaso: tratamento 1, controle (ração); tratamento 2, ração com probiótico 1 (Bifidobacterium); e tratamento 3, ração com probiótico 2 (Lactobacillus). O experimento foi dividido em duas fases, cada uma caracterizada pela mudança da dieta de qualidades diferentes. Ao exame ultrassonográfico, foi avaliada a espessura da parede gastrintestinal, e ao radiográfico, a presença de gás em alças intestinais e o espessamento da parede. Observou-se aumento da espessura da parede das alças intestinais $(\mathrm{P}<0,05)$, nos animais dos grupos tratados com probiótico 1 e $2(5,74 \mathrm{~mm}$ e 6,01mm, respectivamente) em relação aos do grupo-controle $(5,03 \mathrm{~mm})$. O uso de probióticos não influenciou a produção de gás intestinal. Não houve diferença $(\mathrm{P}>0,05)$ entre os tratamentos quanto ao escore de gás intestinal. A avaliação quantitativa permitiu a determinação de um escore de gás intestinal, de forma não invasiva, por meio do software Image $\mathbf{J}^{\circledR}$. Concluiu-se que o diagnóstico por imagem sustenta a recomendação dessa metodologia como ferramenta auxiliar na avaliação nutricional de dietas para cães.
\end{abstract}

Palavras-chave: cão, ultrassonografia, radiografia, probióticos

\begin{abstract}
The effects of supplementation with types of probiotics for beagle puppies that received high and low quality diets on the findings of imaging techniques were evaluaded. Eighteen animals were distributed in three randomized treatments: 1, control (diet), 2, diet with a probiotic (Bifidobacterium), and 3, diet with another probiotic (Lactobacillus). The experiment was divided into two phases each characterized by a change of diet. By ultrasonography, the thickness of the gastrointestinal wall was evaluated as well the presence of gas in the bowel and thickening of the wall by radiography. There was an increase in the thickness of the intestinal wall $(P<0.05)$ in animals treated with probiotic, groups 1 and $2,((5,74 m m$ and $6,01 \mathrm{~mm}$, respectively) compared to the control group $(5,03 \mathrm{~mm})$. The use of probiotics did not influence the production of intestinal gas. No significant differences $(P>0.05)$ were observed among treatments for scores of intestinal gas. The quantitative analysis allowed the determination of a score of intestinal gas, noninvasively, using the software Image $J$ @. It was concluded that the imaging technique supports the recommendation of this method as an auxiliary tool in nutritional assessment of diets for dogs.
\end{abstract}

Keywords: dog, ultrasonography, radiography, probiotics

Recebido em 6 de abril de 2009

Aceito em 20 de agosto de 2010

E-mail: marcusfeliciano@yahoo.com.br 


\section{INTRODUÇÃO}

Segundo Nunes (1998), o modo de ação dos probióticos consiste na produção de peróxido de hidrogênio - que apresenta ação bactericida -, de substâncias antibióticas, de enzimas digestivas cuja função assume maior importância em animais jovens - e de vitaminas do complexo B, que previnem o acúmulo de aminas tóxicas e amônia e estimulam o apetite, cujo mecanismo é desconhecido.

Os primeiros relatos do uso da ultrassonografia no trato gastrintestinal de pequenos animais iniciaram-se a partir de 1989 (Penninck et al., 1989). Esses autores descreveram que as cinco camadas intestinais identificadas pela ultrassonografia são, na direção do lúmen para fora: (1) mucosa, visibilizada como uma linha hiperecoica em contato com o lúmen; (2) mucosa-hipoecoica; (3) submucosa-hiperecoica; (4) muscular própria-hipoecoica; e (5) subserosa/serosa-hiperecoica.

Penninck (2002) citou que os fatores que limitam a ultrassonografia nos segmentos intestinais de pequenos animais são a variabilidade do conteúdo intraluminal gasoso, a dificuldade de identificação do segmento intestinal acometido e a resolução da imagem dos equipamentos e transdutores. Já no lúmen, são descritos quatro tipos de constituintes: (1) fluido anecoico; (2) muco, que se apresenta como material ecogênico sem sombreamento acústico; (3) ar, apresentando reflexão com sombreamento acústico; e (4) alimento, anecoico com pontos ecogênicos (Froes, 2004).

O espessamento da parede gastrintestinal é o achado sonográfico mais comumente visibilizado em casos de doença inflamatória do trato gastrintestinal (Baber e Mahaffey, 1998). Essa inflamação é caracterizada por espessamento mais extenso, com a estratificação das camadas parietais preservadas, ou seja, as camadas apresentam-se bem diferenciadas, com nítido predomínio da visibilização da camada submucosa. A doença inflamatória gastrintestinal também apresenta linfadenomegalia mesentérica (aumento de tamanho dos linfonodos e de sua ecogenicidade), que é relativamente comum na doença ativa (Penninck et al., 1990).
O trato gastrintestinal é visibilizado, nas radiografias, devido ao contraste de gordura, mesentério e omento com o conteúdo luminal (Burk e Ackerman, 1996). Segundo Koide et al. (2000), o gás intestinal é facilmente identificável em radiografias abdominais, como uma imagem radiotransparente, sendo de grande uso no diagnóstico das afecções intestinais. A quantidade de gás e sua extensão são consideradas um reflexo da função intestinal. Assim, podem estar normais, aumentadas ou diminuídas, de acordo com os diversos estados patológicos, fisiológicos ou nutricionais. Porém, a avaliação dessa quantidade de gás torna-se muito subjetiva.

O gás, presente no tubo digestivo, produz imagens que permitem reconhecer os diferentes segmentos intestinais (Cortés, 2002). Koide et al. (2000) realizaram um trabalho em que radiografias foram escaneadas e, por meio de um software, traçou-se a área de regiões intestinais com gás, calculou-se o volume e definiu-se um escore de volume de gás. É, dessa forma, um método não invasivo e promissor na medicina veterinária.

O objetivo deste trabalho foi avaliar os efeitos da suplementação de dois tipos de probióticos para cães filhotes da raça Beagle, que receberam dois tipos de dieta de alta e de baixa qualidade, sobre os achados em exames de diagnóstico por imagem.

\section{MATERIAL E MÉTODOS}

Foram utilizados 18 cães da raça Beagle, filhotes de dois-seis meses de idade, saudáveis, distribuídos ao acaso em três tratamentos: (1) administração somente de ração (controle); (2) administração de ração + probiótico 1; e (3) administração de ração + probiótico 2 .

O experimento foi dividido em duas fases: (1) avaliação e comparação dos efeitos dos probióticos com a mudança de uma dieta de alta qualidade (Superpremium) para uma dieta comercial padrão (Standard); e (2) avaliação e comparação dos efeitos dos probióticos com a mudança de uma dieta comercial Standard para uma dieta Superpremium. As terminologias Standard e Super Premium são usuais na indústria de alimentos comerciais para cães e entre os consumidores. Essas denominações 
serão utilizadas ao longo deste trabalho para denominar as dietas de qualidade padrão e superior, respectivamente.

O probiótico 1 continha em sua formulação

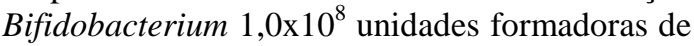
colônia por grama (UFC/g), Lactobacillus $9,1 \times 10^{7} \mathrm{UFC} / \mathrm{g}$ e Enterococcus $1,2 \times 10^{8} \mathrm{UFC} / \mathrm{g}$. A composição do probiótico 2 era Lactobacillus $4,3 \times 10^{8} \mathrm{UFC} / \mathrm{g}$, Enterococcus $3,1 \times 10^{8} \mathrm{UFC} / \mathrm{g}$ e Pediococcus $3,5 \times 10^{8} \mathrm{UFC} / \mathrm{g}$.

$\mathrm{Na}$ primeira fase, os animais passaram por adaptação nutricional de 11 dias, de acordo com Swanson et al. (2002), com ração Superpremium. No $12^{\circ}$ dia foi instituído jejum de 24 horas e, no $13^{\circ}$ dia, os animais passaram a receber ração Standard e se iniciou a suplementação com probióticos via oral. Previamente ao jejum de 24 horas e à troca da ração, foram realizados os exames ultrassonográficos e radiográficos, com exceção do tratamento-controle, a cada 12 horas, na posologia recomendada pelo fabricante - três gramas diários para cada cão, recomendados para animais em estresse ou doença inflamatória do trato gastrintestinal -, durante três dias consecutivos. No último dia de administração dos probióticos, foram repetidos os exames ultrassonográficos e radiográficos para cada tratamento.

A ração comercial Standard foi fornecida por sete dias. No sétimo dia, foram realizados os exames de diagnóstico por imagem, que serviram como parâmetros para a Fase 2.

$\mathrm{Na}$ segunda fase, os animais passaram por adaptação nutricional de sete dias com ração comercial Standard, seguida pela troca da ração para a Superpremium, antes da suplementação com os probióticos. Igualmente à Fase 1, no dia anterior à troca, os animais foram submetidos a jejum de 24 horas. Os demais procedimentos foram semelhantes aos executados na Fase 1.

A diferença observada nos períodos de adaptação das Fases 1 e 2 (11 dias e sete dias de adaptação, respectivamente) foi devido à adequação da metodologia, pois, para utilização dos aparelhos radiográfico e ultrassonográfico, foram necessários agendamentos para uso do equipamento e disponibilidade dos responsáveis pelo serviço. Entretanto, o período mínimo de adaptação foi preservado.
Ao exame ultrassonográfico, foi avaliada a espessura da parede do cólon, buscando-se aspectos ultrassonográficos compatíveis com doença inflamatória gastrintestinal, segundo Froes (2004). Procurou-se identificar as cinco camadas da alça intestinal bem como o aspecto ultrassonográfico de seu conteúdo, e realizou-se a mensuração da espessura em milímetros. Assim, como um dos objetivos era avaliar se os probióticos seriam capazes de prevenir o aparecimento de doença inflamatória na presença de um fator estressante como a troca de ração, o exame teve que ser realizado após o período de adaptação. Para o exame, foi utilizado o aparelho Toshiba ${ }^{\circledR}$ SSH-140A, com transdutor convexo de $3,75 \mathrm{MHz}$ e transdutor linear de $7,5 \mathrm{MHz}$.

Ao exame radiográfico, foram avaliados a presença de gás no cólon e o espessamento da parede deste segmento. $\mathrm{O}$ equipamento utilizado foi o aparelho radiográfico Meditronix ${ }^{\circledR}$ BR-200 e os filmes radiográficos $\operatorname{Kodak}^{\circledR}$ tamanho $24 \times 30 \mathrm{~cm}$. Os animais foram radiografados na projeção laterolateral esquerda.

Após análise qualitativa das radiografias, realizada por meio de observação visual do total de gás no cólon por um especialista em radiologia, foi dado um escore de gás intestinal de 1 a 3 - pouca, moderada e grande quantidade de gás, respectivamente -, adaptado do descrito em medicina humana por Koide et al. (2000), mas ainda inédito em medicina veterinária.

A análise quantitativa das radiografias foi realizada com auxílio do programa computacional Image $\mathbf{J}^{\circledR}$, disponibilizado pelo Departamento de Engenharia Agrícola da Universidade Federal de Lavras. Para esta análise, todas as radiografias foram fotografadas por uma câmera digital, Sony ${ }^{\circledR} 7.2$ megapixels, para posterior análise.

As radiografias foram fotografadas com câmera digital, demarcando-se o segmento de cólon a ser estudado, com uma régua graduada em centímetros. As análises basearam-se em segmentação da área do cólon desejada, por meio de limiares de contraste, threshold e análise da área correspondente à porção segmentada e correspondente ao gás intestinal. Os limiares de contraste foram ajustados para cada imagem, que trazia uma referência de tamanho por meio de uma régua graduada em centímetros. 
Os dados provenientes das áreas analisadas pelo software foram comparados com os da avaliação de um especialista em radiologia, que atribuía o grau de concentração de gás de acordo com uma escala de valores de 1 a 3 .

O delineamento experimental utilizado foi o inteiramente ao acaso, com três tratamentos e seis repetições, totalizando 18 unidades experimentais. Os dados foram previamente testados para normalidade dos resíduos e homogeneidade das variâncias (teste F). Quando essas premissas não eram respeitadas, era realizada a transformação logarítmica. As médias reais ou transformadas foram avaliadas por meio de análise de variância, e a comparação de médias pelos testes Tukey e $t$, no PROC MEANS-SAS ${ }^{\circledR}$. As variáveis qualitativas, como o escore de gás intestinal, foram avaliadas pelo teste Kruskal-Wallis.

\section{RESULTADOS E DISCUSSÃO}

Os valores médios de espessura da parede intestinal (EPI) nas Fases 1 e 2, caracterizadas pelas trocas de dietas, encontram-se nas Tab. $1 \mathrm{e}$ 2.

Tabela 1. Valores médios de espessura da parede intestinal, em mm, avaliados por meio do exame ultrassonográfico, caracterizados pela troca de uma dieta Superpremium para uma dieta comercial Standard, dois tipos de probióticos, para filhotes de cães Beagle, na Fase 1 do experimento

\begin{tabular}{cccc}
\hline \multirow{2}{*}{ Época } & \multicolumn{3}{c}{ Tratamento } \\
\cline { 2 - 4 } & Controle & Probiótico 1 & Probiótico 2 \\
\hline 1 & $4,87 \pm 0,69$ & $4,64 \pm 0,49$ & $4,48 \pm 0,42$ \\
2 & $5,14 \pm 0,58$ & $4,79 \pm 0,37$ & $4,75 \pm 0,51$ \\
\hline CV $(\%)$ & & 10,94 & \\
\hline
\end{tabular}

Época: primeira (1) e última (2) época (terceiro dia) de realização do exame ultrassonográfico.

Probiótico 1: Bifidobacterium; probiótico 2: Lactobacillus.

CV: coeficiente de variação.

Tabela 2. Valores médios de espessura da parede intestinal, em $\mathrm{mm}$, avaliados por meio do exame ultrassonográfico, caracterizados pela troca de uma dieta comercial Standard para uma dieta Superpremium, dois tipos de probióticos, para filhotes de cães Beagle, na Fase 2 do experimento

\begin{tabular}{cccc}
\multirow{2}{*}{ Época } & \multicolumn{3}{c}{ Tratamento } \\
\cline { 2 - 4 } & Controle & Probiótico 1 & Probiótico 2 \\
\hline 1 & $5,42 \pm 0,44$ & $5,45 \pm 0,53$ & $5,52 \pm 0,48)$ \\
2 & $5,03 \pm 0,66 \mathrm{~A}$ & $5,74 \pm 0,59 \mathrm{~B}$ & $6,01 \pm 0,73 \mathrm{~B}$ \\
\hline $\mathrm{CV}(\%)$ & & 11,06 & \\
\hline
\end{tabular}

Época: primeira (1) e última (2) época (terceiro dia) de realização do exame ultrassonográfico.

Probiótico 1: Bifidobacterium; probiótico 2: Lactobacillus.

Médias seguidas de letras distintas na linha diferem entre si pelo teste $t$.

CV: Coeficiente de variação.

Houve aumento médio na espessura da parede das alças intestinais na Fase 2, isto é, nos animais tratados com probiótico, a camada intestinal era mais espessa se comparada à dos animais do grupo-controle.

Penninck et al. (1990) relataram como achado ultrassonográfico sugestivo de inflamação intestinal a preservação da estratificação das camadas parietais, ou seja, as camadas apresentam-se bem diferenciadas, com nítido predomínio da visibilização da camada submucosa. No presente experimento, embora tenha sido observado espessamento, não foi visibilizada essa característica ultrassonográfica relacionada à inflamação. Sugere-se que, devido às condições saudáveis dos animais, não houve aumento da espessura em consequência das alterações inflamatórias, e sim aumento que sugeriria explicação do achado nas camadas da parede das alças intestinais. Na Fig. 1, mostra-se a imagem ultrassonográfica abdominal normal, e na Fig. 2 a imagem ultrassonográfica do cólon de cão do tratamento 2, com mensuração da espessura e avaliação morfológica das camadas murais. 


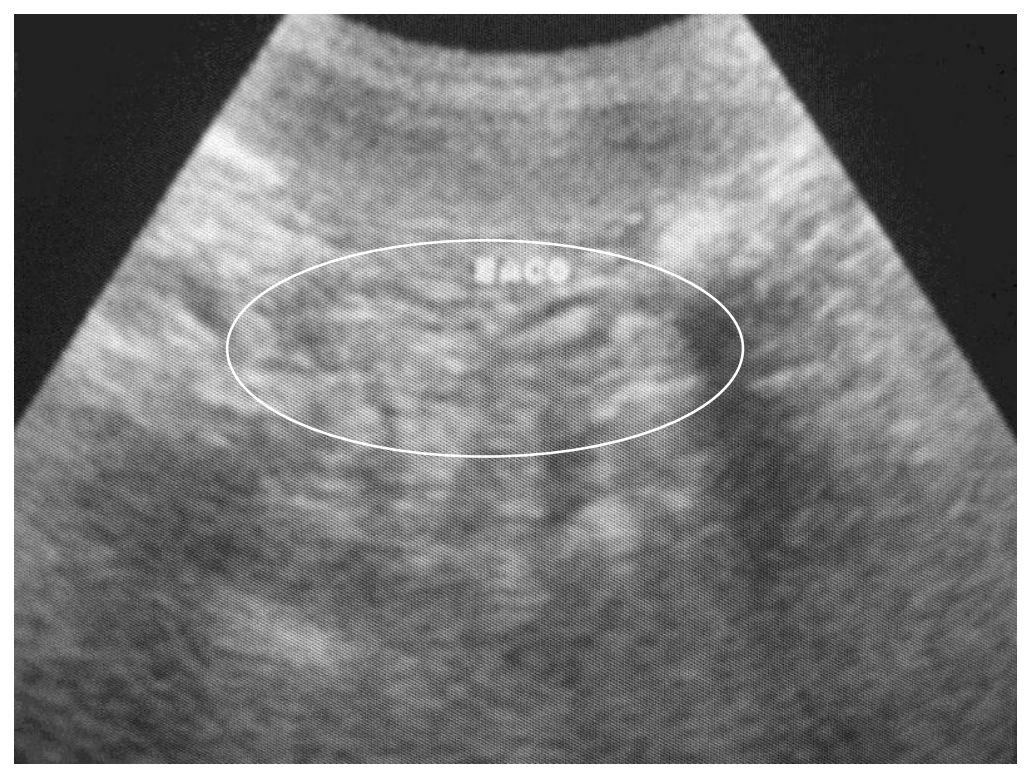

Figura 1. Imagem abdominal ultrassonográfica panorâmica, realizada com transdutor de $3,75 \mathrm{MHz}$, de cão filhote da raça Beagle, mostrando as alças intestinais (circundadas).

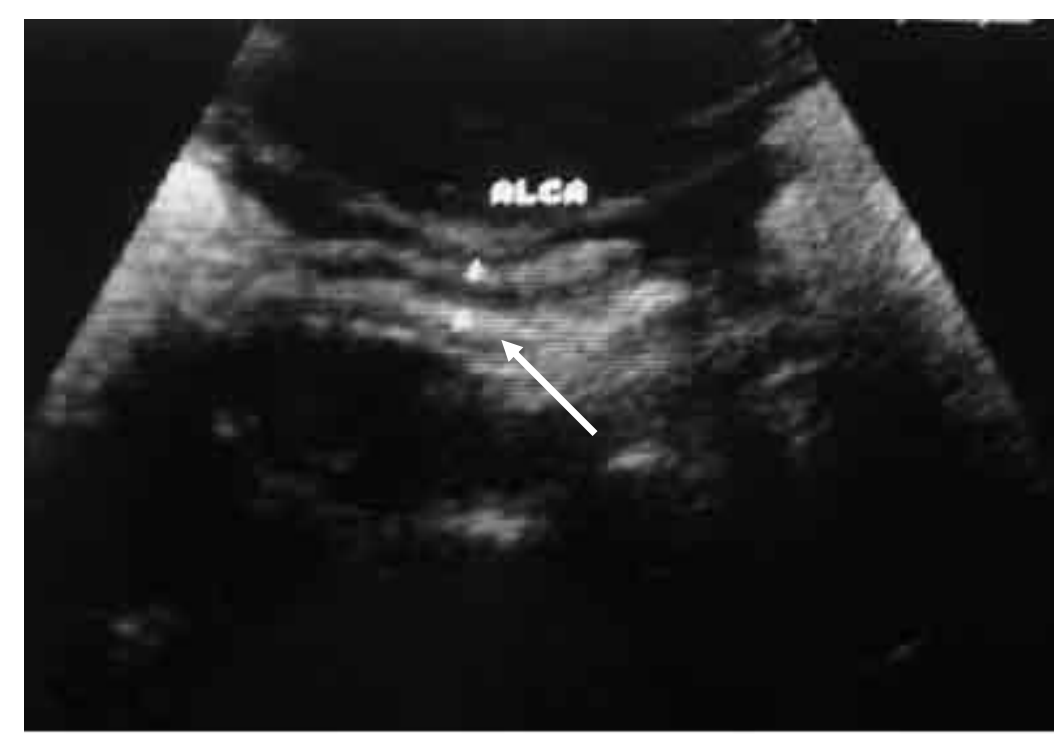

Figura 2. Imagem ultrassonográfica, realizada com transdutor de $3,75 \mathrm{MHz}$, de cão filhote da raça Beagle, do tratamento com probiótico 2 (Lactobacillus), com mensuração da espessura e avaliação morfológica das camadas murais (seta).

Outro fator importante para embasar tal hipótese é a não visibilização de linfonodomegalia mesentérica e o aumento de sua ecogenicidade, diferentemente dos achados citados na literatura em doenças inflamatórias (Penninck et al., 1990).
Os valores médios de área de gás intestinal, ao exame radiográfico, em centímetros quadrados, nas Fases 1 e 2, caracterizados pelas trocas de dietas, encontram-se nas Tab. 3 e 4. 
Tabela 3. Valores médios de área de gás intestinal ao raio-x, em $\mathrm{cm}^{2}$, caracterizados pela troca de uma dieta Superpremium para uma dieta comercial Standard, dois tipos de probióticos, para filhotes de cães Beagle, na Fase 1 do experimento

\begin{tabular}{cccc}
\hline \multirow{2}{*}{ Época } & \multicolumn{3}{c}{ Tratamento } \\
\cline { 2 - 4 } & Controle & Probiótico 1 & Probiótico 2 \\
\hline 1 & $5,49 \pm 3,44 \mathrm{Aa}$ & $1,99 \pm 0,77 \mathrm{Aab}$ & $0,63 \pm 0,50 \mathrm{~b}$ \\
2 & $1,25 \pm 0,77 \mathrm{~B}$ & $0,67 \pm 0,50 \mathrm{~B}$ & $1,51 \pm 0,99$ \\
\hline $\mathrm{CV}(\%)$ & & 64,95 & \\
\hline
\end{tabular}

Época: primeira (1) e última (2) época (terceiro dia) de realização do exame ultrassonográfico.

Probiótico 1: Bifidobacterium; probiótico 2: Lactobacillus.

Médias seguidas de letras maiúsculas distintas na coluna e minúsculas distintas na linha diferem entre si pelo teste $\mathrm{t}$ a $5 \%$ de significância.

CV: razão entre desvios-padrão e médias, calculada pelo programa SAS/1985.

Tabela 4. Valores médios de área de gás intestinal ao raio-x, em $\mathrm{cm}^{2}$, caracterizados pela troca de uma dieta comercial Standard para uma dieta Superpremium, dois tipos de probióticos, para filhotes de cães Beagle, na Fase 2 do experimento

\begin{tabular}{cccc}
\hline \multirow{2}{*}{ Época } & \multicolumn{3}{c}{ Tratamento } \\
\cline { 2 - 4 } & Controle & Probiótico 1 & Probiótico 2 \\
\hline 1 & $5,99 \pm 4,20$ & $2,14 \pm 1,54$ & $0,96 \pm 1,47$ \\
2 & $3,02 \pm 2,84$ & $3,05 \pm 2,71$ & $1,73 \pm 1,83$ \\
\hline CV $(\%)$ & & 70,88 &
\end{tabular}

Época: primeira (1) e última (2) época (terceiro dia) de realização do exame ultrassonográfico.

Probiótico 1: Bifidobacterium; probiótico 2: Lactobacillus.

CV: coeficiente de variação.

Na Fase 1, houve diminuição da área de gás intestinal ao exame radiográfico, nos animais do grupo-controle e do tratamento 1 , em relação aos momentos das radiografias realizadas 24 horas antes da mudança da dieta e no terceiro dia de administração do probiótico. Observou-se que houve diferença entre os animais tratados com probióticos e os do controle, no primeiro momento (24 horas antes da mudança da dieta), mas isso não pôde ser notado na segunda coleta. Dessa forma, pode-se inferir que o uso de probióticos não influenciou a produção de gás intestinal, pois, no segundo momento (terceiro dia de administração do probiótico), não houve diferença entre os grupos analisados.

Na Fase 2, houve diferença entre os tratamentos, isto é, houve aumento na produção de gás nos dos grupos tratados com probiótico e diminuição na área de gás nos do grupo-controle.

Diferentemente ao proposto por Koide et al. (2000), foi possível quantificar, por meio do software Image $\mathbf{J}^{\circledR}$, nas radiografias digitalizadas, a área do gás intestinal, não mais se tratando de uma medida subjetiva (Fig. 3 e 4).
Há várias causas fisiológicas e patológicas de aumento na produção de gás pelo intestino grosso, no entanto, em relação às causas relacionadas com o uso de probióticos, de acordo com Swanson et al. (2002), a suplementação com probióticos pode aumentar a quantidade de substrato para as bactérias redutoras de enxofre, aumentando as concentrações de compostos sulfúricos nas fezes. Como consequência desse processo, há aumento da quantidade de gás no intestino grosso. Neste experimento, pôde-se observar que, na Fase 2, foram encontradas médias e diferenças na quantidade de gás intestinal entre os tratamentos, embasando essa citação. Entretanto, na Fase 1, não houve correlação entre os achados citados pelos autores mencionados.

Não houve diferença entre os tratamentos em relação ao escore de gás intestinal (Tab. 5 e 6). A Fig. 5 correlaciona a avaliação quantitativa com a qualitativa da quantidade de gás intestinal, sugerindo graduação. Nesta figura, há correlação entre a área e o escore de gás intestinal. 


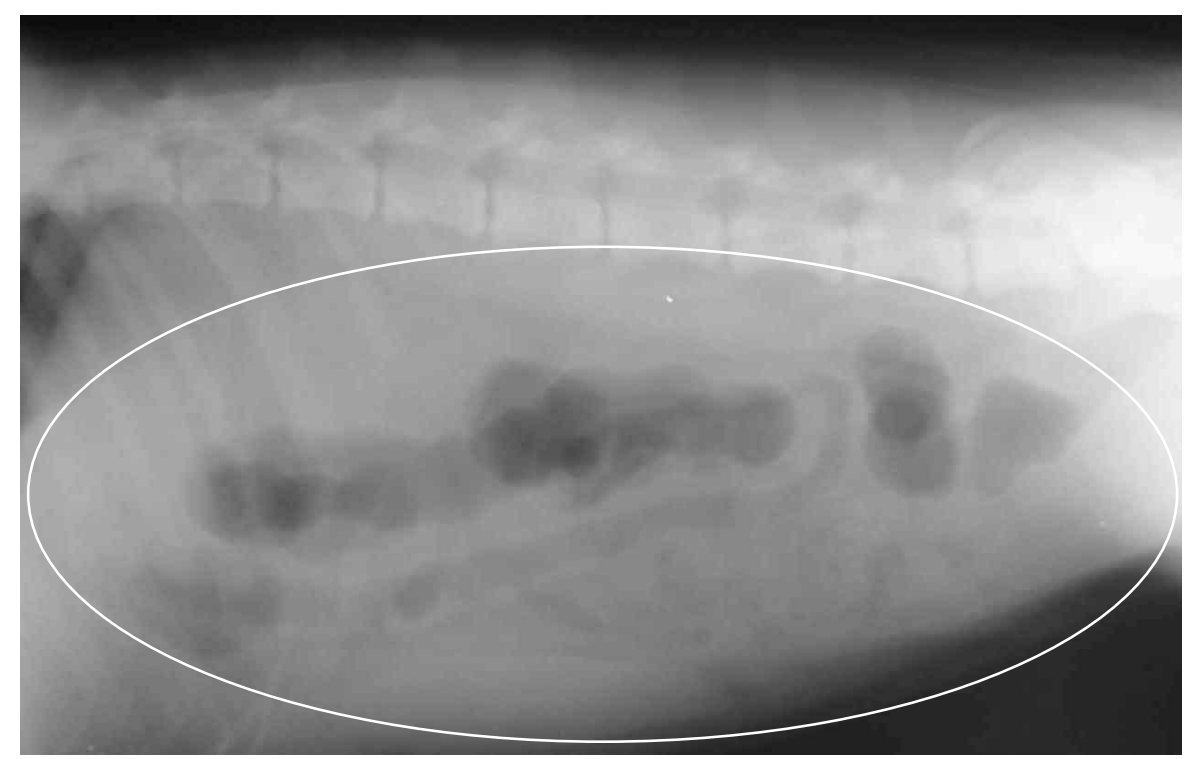

Figura 3. Radiografia abdominal panorâmica, de cão filhote Beagle, na projeção laterolateral. Notam-se alças intestinais (circundadas) com presença de gás, formando uma imagem radiotransparente.

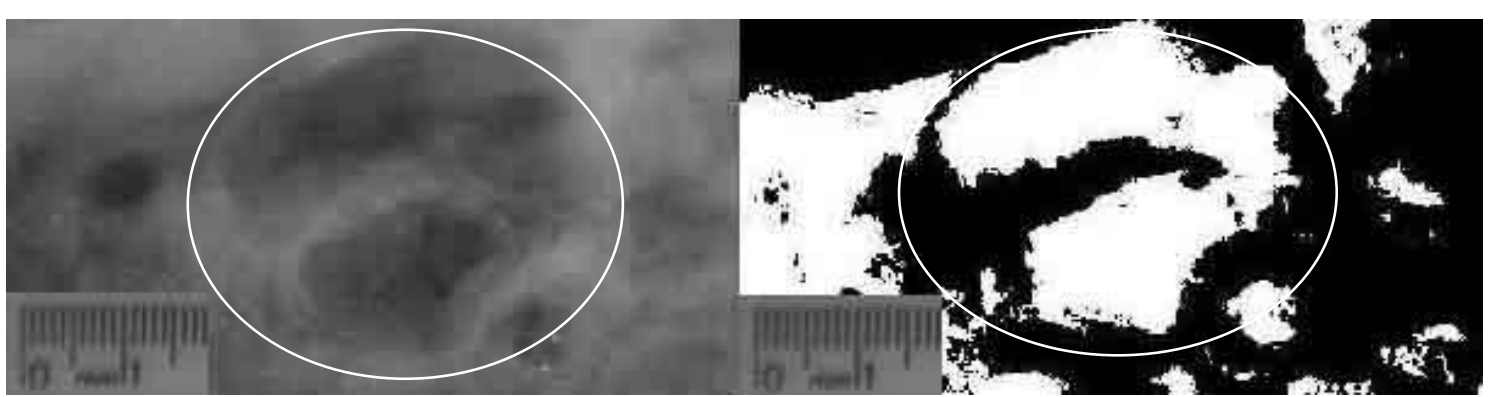

Figura 4. Detalhe de radiografia abdominal de cão filhote Beagle, na projeção laterolateral. Notam-se alças intestinais (circundadas à esquerda) com presença de gás, formando uma imagem radiotransparente. A imagem à direita ilustra a mesma radiografia processada no programa computacional Image $\mathbf{J}^{\circledR}$. Nota-se melhor distinção entre área de gás e alças intestinais (circundadas à direita).

Tabela 5. Escores médios de gás intestinal ao raio-x, em função dos tratamentos estudados, dois tipos de probióticos, para filhotes de cães Beagle, na Fase 1 do experimento

\begin{tabular}{lc}
\hline Tratamento & Escore médio \\
\hline Controle / Superpremium & 2,0 \\
Controle / Standard & 1,3 \\
Probiótico 1 / Superpremium & 1,8 \\
Probitótico 1 / Standard & 1,7 \\
Probiótico 2 / Superpremium & 2,0 \\
Probiótico 2 / Standard & 1,5 \\
\hline P > Qui-quadrado & 0,3284 \\
\hline Probiótico 1: Bifidobacterium; & probiótico 2:
\end{tabular}

Tabela 6. Escores médios de gás intestinal ao raio-x, em função dos tratamentos estudados, dois tipos de probióticos, para filhotes de cães Beagle, na Fase 2 do experimento

\begin{tabular}{lc}
\hline Tratamento & Escore médio \\
\hline Controle / Superpremium & 2,1 \\
Controle / Standard & 1,8 \\
Probiótico 1 / Superpremium & 1,5 \\
Probitótico 1 / Standard & 1,6 \\
Probiótico 2 / Superpremium & 2,0 \\
Probiótico 2 / Standard & 2,0 \\
\hline P > Qui-quadrado & 0,5959 \\
\hline Probiótico 1: Bifidobacterium; & probiótico 2: \\
Lactobacillus.
\end{tabular}




\section{Escore de gás intestinal}

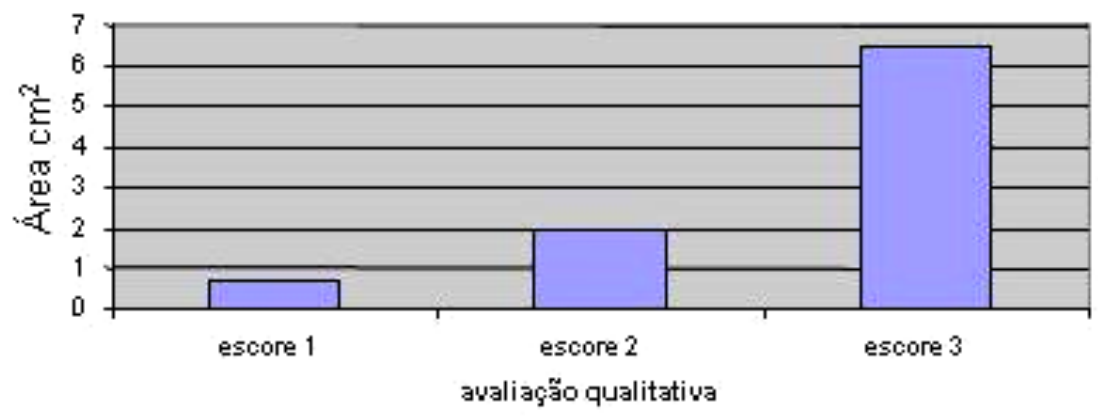

Figura 5. Escore de gás intestinal obtido por avaliação qualitativa, por meio da análise das áreas intestinais de radiografias, em cães filhotes Beagle tratados com dois tipos de probióticos.

O método proposto permitiu a determinação de um escore, ou seja, uma avaliação quantitativa da presença de gás intestinal. Além disso, foi possível correlacionar este escore com a avaliação proveniente de um especialista, com imagens digitalizadas e processadas. A avaliação quantitativa, ainda não descrita na literatura médica veterinária, permitiu a determinação de um escore de gás intestinal, de forma não invasiva, por meio do software Image $\mathbf{J}^{\circledR}$.

A melhoria da correlação poderá ser conseguida com a transformação das áreas em volume, a partir dos dados obtidos em duas dimensões. A maior automação do processo irá depender do desenvolvimento de programas capazes de simular a interpretação humana, porém sem saber da real necessidade frente ao que já está sendo disponibilizado pela análise computacional proposta.

\section{CONCLUSÕES}

Os resultados significativos dos exames de diagnóstico por imagem sustentam a recomendação desta metodologia como ferramenta auxiliar em avaliações nutricionais de dietas e suplementação de probióticos para cães. Entretanto, é conveniente salientar que o método utilizado para averiguar a área de gás intestinal e seu programa são recentes e necessitam de aperfeiçoamento para adequar as imagens realizadas e o mecanismo de mensuração da área de gás.

\section{REFERÊNCIAS BIBLIOGRÁFICAS}

BABER, D.L.; MAHAFFEY, M.B. The stomach. In: THRALL, D.E. (Ed). Textbook of veterinary diagnostic radiology. 3.ed. Philadelphia: W.B. Saunders, 1998. p.520539.

BURK, R.L.; ACKERMAN, N. The abdomen. In: Small animal radiology and ultrasonography: a diagnostic atlas and text. 2.ed. Philadelphia: W.B. Saunders, 1996. p.296-310.

CORTÉS, C. Gases del abdome y su utilidad diagnostica: gases endoluminales. Rev. Chilena Radiol., v.8, p.5-12, 2002.

FROES, T.R. Ultrassonografia do trato gastrointestinal. In: CARVALHO, C.F. (Ed). Ultrassonografia em pequenos animais. São Paulo: Roca, 2004. p.147-164.

KOIDE, A.; YAMAGUCHI, T.; ODAKA, T. et al. Quantitative analysis of bowel gas using plain abdominal radiograph in patients with irritable bowel syndrome. Am. $J$. Gastroenterol., v.95, p.1735-1741, 2000.

NUNES, I.J. Nutrição animal básica. Arq. Bras. Med. Vet. Zootec., v.2, p.388, 1998

PENNINCK, D.G.; NYLAND, T.G.; FISHER, P.E. Ultrasonography of the normal canine gastrointestinal tract. Vet. Radiol. Ultrasound, v.30, p.272-276, 1989.

PENNINCK, D.G.; NYLAND, T.G.; KERR, L.Y.; FISHER, P.E. Ultrasonographic evaluation of gastrointestinal disease in small animals. Vet. Radiol. Ultrasound, v.31, p.134-141, 1990.

PENNINCK, D.G. Gastrointestinal tract. In: NYLAND, T.G.; MATTOON, J.S. (Eds). Small animal diagnostic ultrasound. 2.ed. Philadelphia: W.B. Saunders, 2002. p.207230.

SWANSON, K.S.; GRIESHOP, C.M.; FLICKINGER, E.A. et al. Fructooligosaccharides and Lactobacillus acidophilus modify gut microbial populations, total tract nutrients digestibilities and fecal protein catabolite concentrations in healthy adult dogs. J. Nutr., v.132, p.3721-3731, 2002. 